\title{
Three decades of publishing research in population economics
}

\author{
Alessio J. G. Brown ${ }^{1}$ - Klaus F. Zimmermann ${ }^{1,2}$
}

Published online: 13 October 2016

(C) Springer-Verlag Berlin Heidelberg 2016

\begin{abstract}
The Journal of Population Economics is celebrating its 30th birthday. When the first issue was published, population economics was non-existent as a field. Hence, the aim has been to provide a high-quality outlet to publishing excellent theoretical and applied research in all areas of population economics. The article summarizes key developments in the Journal's editorial process, thematic orientation, international reach, and successes. Furthermore, we discuss the benefits of working papers in economics and investigate the impacts of the current working paper culture on journal citations. Finally, we try to identify the citation impacts in the Journal itself. The Journal of Population Economics has established itself as the leader in its field. Publishing in working papers and in the Journal seem to be complementary activities.
\end{abstract}

Keywords Demographical economics - Population economics · Working papers · Kuznets prize . Citation impacts

JEL classification A11 · A14 · B20 · J1

\footnotetext{
We are indebted to Milena Nikolova, former Managing Editor of the Journal of Population Economics, for her great support for this article. We also thank Daria Golokhvastova, Anna Schwippert, and Sarah Stahlmann for excellent research assistance. We are also very grateful to Anna Cardoso, Margard Ody, and Maria Muskalla for various valuable help and advice.
}

This paper was written on the occasion of the 30th anniversary of the Journal of Population Economics by the Editor-in-Chief and the Managing Editor of the Journal

Klaus F. Zimmermann

klaus.f.zimmermann@gmail.com

1 UNU-MERIT, Maastricht, The Netherlands

2 Harvard University, Cambridge, MA, USA 


\section{Introduction}

Throughout the last three decades, the Journal of Population Economics, an international quarterly journal that publishes original theoretical and applied research in all areas of population economics, has been at the forefront of population economics research. ${ }^{1}$ The issues stretched from micro-level topics as individual, household, or family behavior, including household formation, marriage, divorce, fertility choices, education, labor supply, migration, health, risky behavior, and aging to macro-level analyses as economic growth with exogenous or endogenous population evolution, population policy, savings and pensions, social security, housing, and health care.

Moreover, the Journal has also featured research into economic approaches to human biology, the relationship between population dynamics and public choice, and the impact of population on the distribution of income and wealth. In addition, the Journal has attracted papers dealing with policy issues and development problems that are relevant to population questions. Today, issues related to population economics such as the demographic composition of the labor force, including aging populations, migration and refugees, declining fertility rates, and many more policy-relevant topics have been at the fore. With the aim of guiding readers, the Journal traditionally features a lead article with temporary open-access and group articles into thematic clusters.

In its 30 years of publishing high-quality research in population economics, the Journal has experienced exciting developments in its editorial processes, its geographical and thematic perspectives, and its successes in impact and ranking. In the next section of this article, we present some selected aspects of these developments.

The proliferation of working papers and the respective working paper culture in economics has implications for publishing peer-reviewed journal articles. Some journals in demography and other disciplines have been worried about the potential competition working papers may have for journals. In section 3, we, thus, discuss these implications, the benefits and potential costs of working papers. Specifically, we look into the implications for citations. We argue that the dissemination function, the resulting benefits, and resulting early cites clearly outweigh potential citation losses of journal articles. Finally, we try to identify the citation impacts of working papers in the Journal of Population Economics. Section 4 concludes.

\section{Three decades of the Journal of Population Economics}

We focus on several aspects of the Journal's development and position in the field. We first take a closer look at the evidence related to the editorial development of the Journal.

\subsection{Some editorial developments}

Submissions to the Journal of Population Economics have continuously been increasing over time; in the last 20 years, nearly tenfold. This is substantially more than the

\footnotetext{
${ }^{1}$ See Zimmermann (1997).
} 
doubling of submissions to the top five economics journals between 1990 and 2012 as evidenced by Card and DellaVigna (2013), ${ }^{2}$ which can be rationalized by the Journal of Population Economics' younger age and its position as a field journal. The Journal has been receiving over 400 articles per year on average over the last 5 years and is expected to receive over 450 articles in 2016. Figure 1 shows the development of the number of submissions over the last 20 years.

The Journal of Population Economics published between 16 (in the early years) and 61 (in 2013) articles per year. Since 2014 the Editors have established a strict policy of publishing only 10 papers per issue, totaling to 40 papers per year. In total, until the end of 2015, the Journal has published 1007 articles. Figure 1 also shows the development of the number of published articles over the last 20 years. A rising number of papers were published, in particular between 2007 and 2013, with more than 50 articles per year after 2009.

The continuously increasing submissions over time, recently up to well over 400 articles, and the fixed number of 40 published articles per year result in a decreasing acceptance rate well below $10 \%$ in recent years. Again, the reduction in published articles and the decreasing acceptance rate is in line with the trends identified by Card and DellaVigna (2013) for the top five journals in economics. ${ }^{3}$ Figure 2 displays two acceptance rate measures for the last 20 years: acceptance rate 1 is calculated as the number of published articles in a given year as the share of the number of submissions in the given year, and acceptance rate 2 as the number of articles published in a given year divided by the number of previous year's submissions.

In light of these developments and the slowdown in first decision times in economics journals to 3-6 months ${ }^{4}$ in 2013, the Journal has implemented a strict desk rejection policy which aims to provide authors with an early signal for better targeting of their work and at the same time saving editorial and refereeing resources. Furthermore, the average number of days to reach a first decision has been consistently declining for the Journal of Population Economics to 42 days in 2015.

According to Card and DellaVigna (2013), the fall in the number of articles per year in the top five journals was partly offset by an increasing number of coauthors from 1.3 in 1970 to 2.3 in 2012. In line with these trends also, the Journal of Population Economics experienced an increased number of co-authors of published articles over the 30 years. ${ }^{5}$ Specifically, as Fig. 3 illustrates, the Journal had an average of 1.4 authors in 1998 and reached 2.1 in 2015.

We now inspect the development of areas covered in the Journal of Population Economics.

\footnotetext{
${ }^{2}$ Card and DellaVigna (2013) analyzed the following five journals: the American Economic Review (AER), Econometrica (ECA), the Journal of Political Economy (JPE), the Quarterly Journal of Economics (QJE), and the Review of Economic Studies (RES).

${ }^{3}$ Specifically, the acceptance rates decreased from 15 to $6 \%$ between 1990 and 2012; see Card and DellaVigna (2013).

${ }^{4}$ See Azar (2007).

${ }^{5}$ See Andrikopoulos et al. (2016) for a review of the development and determinants of co-authorship in economics as well as an analysis of the structure and network of collaborative authorships.
} 


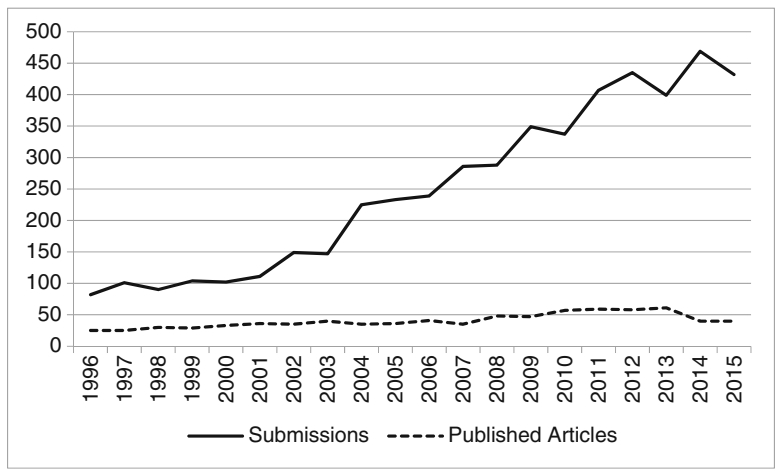

Fig. 1 Development of number of submissions and articles over the last 20 years. Source: own calculations

\subsection{The evolution of JEL areas}

In order to examine the broad JEL areas, the Journal has covered and to investigate whether its focus has remained stable over time, we have calculated the weighted share of JEL codes reported in the Journal's articles for the last 20 years; see Table 1. Not surprising, the Journal has a strong focus on Labor and Demographic Economics, from 1996 to 2005 with a share of above $50 \%$, and in the last 10 years declining to around $45 \%$. The second strongest JEL Code covered is Health, Education, Welfare, which continuously increased from $6 \%$ in the period 1996-2000 to $15 \%$ in 2011-2015. Microeconomics as well as Economic Development, Innovation, Technological Change, and Growth have been traditionally important topics with recent shares of

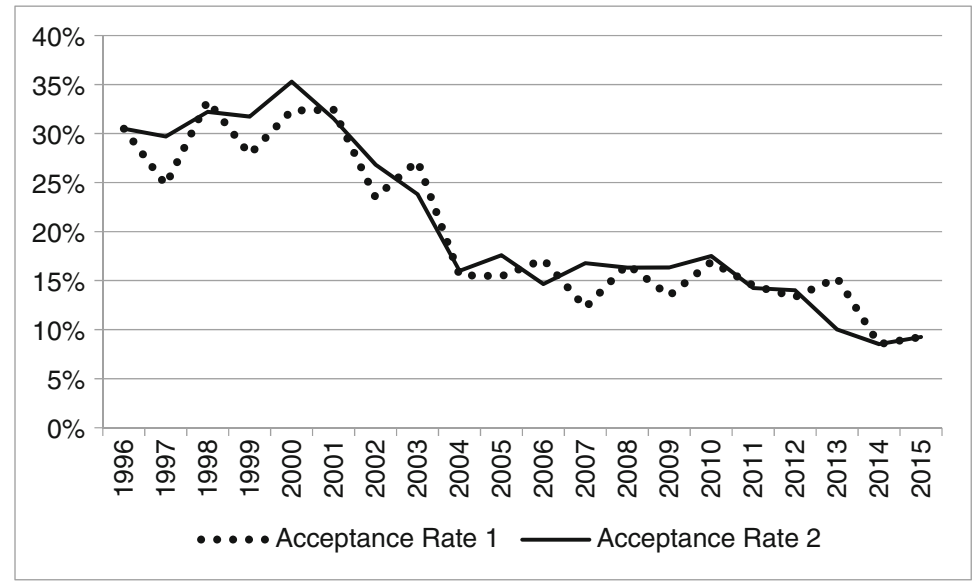

Fig. 2 Development of two acceptance rate measures over the last 20 years. Note: Acceptance rate $1=$ number of published articles in a given year/number of submissions in the given year; acceptance rate $2=$ number of articles published in a given year/number of previous year's submissions. Source: own calculations 


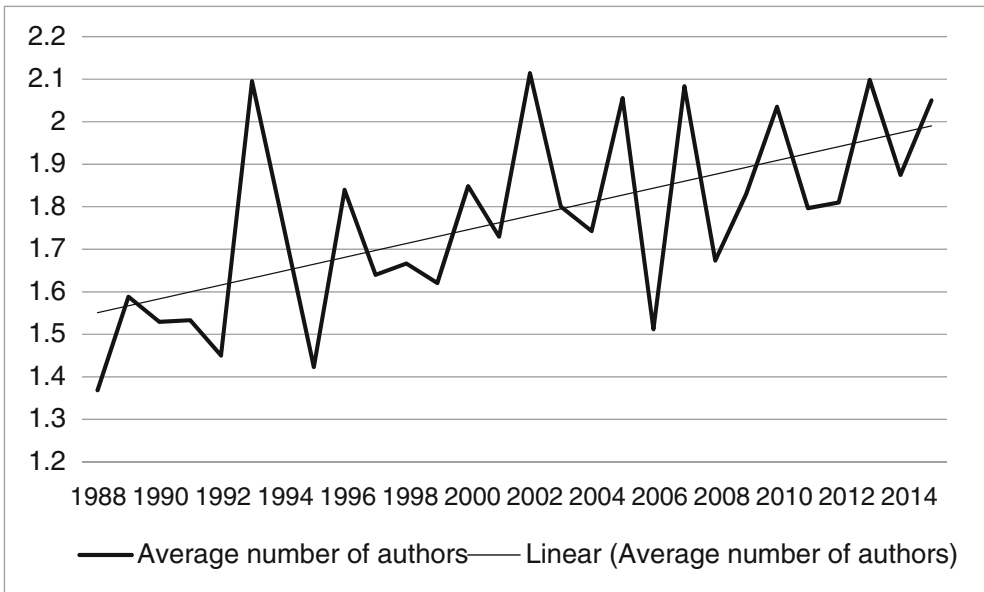

Fig. 3 Average number of authors of published articles in the Journal of Population Economics in 19882015. Note: Yearly averages. Source: own calculations

10 and $8 \%$, respectively. Topics from the classification Mathematical and Quantitative Methods, International Economics, and Public Economics continue being covered by the Journal of Population Economics but on a decreasing level. The coverage of Macroeconomics and Monetary Economics increased over time but remains on a very low level of around $3 \%$.

Table 1 JEL code classifications of published papers, Journal of Population Economics

\begin{tabular}{lllll}
\hline JEL classification & $1996-2000^{\mathrm{a}}$ & $2001-2005$ & $2006-2010$ & 2011-2015 \\
\hline C-Mathematical and Quantitative Methods & 7.96 & 5.64 & 6.44 & 4.25 \\
D-Microeconomics & 7.07 & 9.83 & 11.38 & 10.97 \\
E-Macroeconomics and Monetary Economics & 0.92 & 2.08 & 3.14 & 2.74 \\
F-International Economics & 6.11 & 4.37 & 4.60 & 3.46 \\
H-Public Economics & 5.73 & 6.52 & 5.64 & 4.78 \\
I-Health, Education, Welfare & 5.92 & 7.43 & 10.75 & 14.89 \\
J-Labor and Demographic Economics & 53.41 & 54.20 & 46.65 & 45.66 \\
O-Economic Development, Innovation, & 7.80 & 4.44 & 6.20 & 8.32 \\
$\quad$ Technological Change, and Growth & & & & 7.66 \\
Other & 6.00 & 7.58 & 8.34 & 258 \\
Articles published & 135 & 182 & 228 & 246 \\
Articles published with JEL codes & 135 & 181 & 228 & \\
\hline
\end{tabular}

Average share of JEL codes of Journal of Population Economics articles, weighted by number of codes, from 1996 to 2000 and then 5-year intervals. Source: own calculations

${ }^{a}$ Data only available from the second issue of 1996 


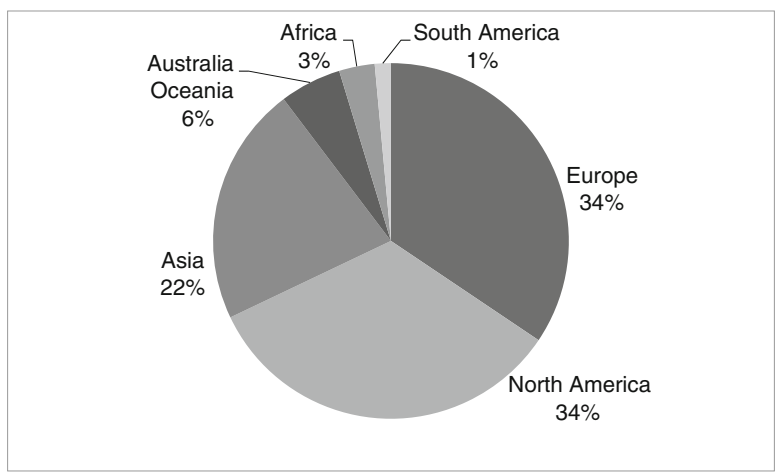

Fig. 4 Visitors at the Journal's publisher website 2013-2015. Source: Springer

In a next step, we take a closer look at whether the Journal's identity as an international outlet is mirrored by its geography of authorship and access.

\subsection{An international journal}

The Journal of Population Economics is an international journal and signals its global focus also in its subtitle: "International Research on the Economics of Population, Household, and Human Resources." We want to assess whether the Journal is globally accessed and inspect the geographical distribution of its authors.

Figure 4 shows that the Journal of Population Economics is globally accessed and read. According to data for 2013-2015 from the Journal's publisher Springer, the top five numbers of clicks came from the USA, followed by the UK, Germany, China, and Australia. With about a third of visits to the Journal's website coming from Europe (34\%) and another third from North America (34\%), followed by a quarter from Asia (22\%), the Journal's presence is certainly global.

Table 2 shows that articles published in the Journal of Population Economics come from authors throughout the world. While on a country level, most articles are published by authors from the USA, from a continent perspective, Europe clearly has the greatest share (on average $54 \%$ ) which has continuously increased over time. North America ranks second with a decreasing share over time (on average $32 \%$ ) and Asia third (with $10 \%$ on average).

Thus, while authorship of the Journal of Population Economics is skewed towards Europe, ${ }^{6}$ its global relevance is well founded on the evidenced global access and readership.

To attract good authors and create attention for their articles, the Journal selects the best paper for a prize, the Kuznets Prize.

\subsection{The Kuznets Prize}

To strengthen excellence in population economics the Journal awards the Kuznets Prize for the best paper published in the Journal of Population Economics. The Prize is

\footnotetext{
${ }^{6} 100 \%$ of authors reported that they would definitely publish or probably publish in the journal again.
} 
Table 2 Origins of submissions 1988-2015

\begin{tabular}{lccccc}
\hline & $1988-1995(\%)$ & $1996-2000(\%)$ & 2001-2005 (\%) & 2006-2010 (\%) & 2011-2015 (\%) \\
\hline Europe & 46.7 & 56.5 & 57.4 & 51.1 & 60.2 \\
North America & 41.8 & 32.2 & 31.9 & 27.7 & 25.8 \\
Asia & 9.0 & 6.9 & 8.0 & 15.3 & 9.9 \\
Australia, Oceania & 2.5 & 4.5 & 2.2 & 4.6 & 2.5 \\
South America & 0.0 & 0.0 & 0.6 & 0.4 & 1.4 \\
Africa & 0.0 & 0.0 & 0.0 & 0.9 & 0.2 \\
\hline
\end{tabular}

Average weighted shares for the respective time periods of all author's affiliations' location by continents for published articles, 1988-2015. Source: own calculation

named after Simon Kuznets, a pioneer in population economics, the late Professor Emeritus at Harvard University, and the 1971 Nobel Prize laureate in economics. Originally covering a 3-year period, starting 1995-1997, since 2014, the Prize has been awarded annually. The papers are nominated and selected by the Editors of the Journal of Population Economics. Table 3 contains all the winning articles.

As a last step in reviewing the evidence of 30 years of the Journal of Population Economics, we highlight the Journal's success in impact and rankings.

\subsection{Successes: impact, citations and rankings}

The Journal of Population Economics is ranked in the Social Science Citation Index since 1994. Figure 5 shows the increase of the Journal's impact factor since 1996, which illustrates its success story.

In 2015, the Simple Impact Factor was 1.139 and the 5-year impact factor was 1.509. IDEAS/RePEc ranks the Journal of Population Economics based on its Simple Impact Factor for Journals as number 70 of 1661 studied journals.

In the next section, we will proceed to discuss the role of working papers in economics and their citation impacts. The debate will include the situation in population economics and relate the analysis to the Journal of Population Economics.

\section{Working papers in (population) economics}

\subsection{Working papers are working}

The internet has enriched scientific communication and dissemination among other means also through the online availability of working papers. While the open dissemination and sharing of unpublished research is very different in various disciplines, economics has a tradition of a working paper culture with a relatively high recognition. ${ }^{7}$ According to McCabe and Snyder (2015) in economics, the share of

\footnotetext{
${ }^{7}$ See Harley and Acord (2011) and Frandsen (2009). Other fields commonly using working papers are physics, mathematics, cognitive science, and quantitative social sciences. Working papers are accordingly often also called discussion papers.
} 
Table 3 Kuznets Prize winners and winning papers

\begin{tabular}{|c|c|c|c|}
\hline Years & Author(s) & Title & Volume, issue \\
\hline 2016 & $\begin{array}{l}\text { Semih Tumen } \\
\text { and Binnur Balkan }\end{array}$ & $\begin{array}{l}\text { Immigration and prices: } \\
\text { quasi-experimental evidence } \\
\text { from Syrian refugees in Turkey }\end{array}$ & $2016,29(3): 657-686$ \\
\hline 2015 & Haoming Liu & $\begin{array}{l}\text { The quality-quantity trade-off: } \\
\text { evidence from the relaxation } \\
\text { of China's one-child policy }\end{array}$ & 2014,27 (2): 565-602 \\
\hline 2014 & Paolo Masella & $\begin{array}{l}\text { National identity and ethnic } \\
\text { diversity }\end{array}$ & $2013,26(2): 437-454$ \\
\hline 2010-2012 & $\begin{array}{l}\text { Richard W. Evans, } \\
\text { Ying-yao Hu and } \\
\text { Zhong Zhao }\end{array}$ & $\begin{array}{l}\text { The fertility effect of catastrophe: } \\
\text { US hurricane births }\end{array}$ & 2010,23 (1): $1-36$ \\
\hline 2007-2009 & $\begin{array}{l}\text { Makoto Hirazawa } \\
\text { and Akira Yakita }\end{array}$ & $\begin{array}{l}\text { Fertility, child care outside the } \\
\text { home, and pay-as-you-go } \\
\text { social security }\end{array}$ & $2009,22(2): 565-583$ \\
\hline 2004-2006 & Jinyoung Kim & $\begin{array}{l}\text { Sex selection and fertility in a } \\
\text { dynamic model of conception } \\
\text { and abortion }\end{array}$ & 2005,18 (1): 41-67 \\
\hline 2001-2003 & $\begin{array}{l}\text { Olympia Bover } \\
\text { and Manuel Arellano }\end{array}$ & $\begin{array}{l}\text { Learning about migration decisions } \\
\text { from migrants: using complementary } \\
\text { datasets to model intra-regional } \\
\text { migrations in Spain }\end{array}$ & 2002,15 (2): $357-380$ \\
\hline 1998-2000 & David C. Ribar & $\begin{array}{l}\text { The socioeconomic consequences } \\
\text { of young women's childbearing: } \\
\text { reconciling disparate evidence }\end{array}$ & 1999,12 (4): $547-565$ \\
\hline 1995-1997 & James R. Walker & $\begin{array}{l}\text { The effect of public policies on } \\
\text { recent Swedish fertility behavior }\end{array}$ & 1995,8 (3): $223-251$ \\
\hline
\end{tabular}

published articles having working papers rose from $15 \%$ in 1995 to over $50 \%$ in 2005. In other fields such as health science, medicine and psychology copyright restrictions prevent pre- or post-publication and working papers are also not common in competitive fields with commercial potential and speedy journal publication as biology or chemistry. The degree of development of a paper also varies across disciplines, e.g., in physics, math, and bioinformatics, working papers often are final version pre-prints. ${ }^{8}$

In economics, working papers can be papers in progress or more polished versions submitted to a journal or forthcoming in a journal, typically complementary to journal publication, while not all working papers are published in journals and not all journal articles exist as working papers. With some exceptions, working papers are typically not refereed. ${ }^{9}$ Besides formal working paper series as the widely followed NBER,

\footnotetext{
${ }^{8}$ See Harley and Acord (2011) and Harley et al. (2010). The ArXiv is a repository of preprints in mathematics, physics, astronomy, computer science, quantitative biology, statistics, and quantitative finance; see Harley et al. (2010).

${ }^{9}$ Some World Bank Discussion Paper Series are refereed; other series have some moderating role or quality control by the editor and series as NBER and CEPR are affiliation-based, i.e., you need to be a fellow to submit a paper in these series.
} 


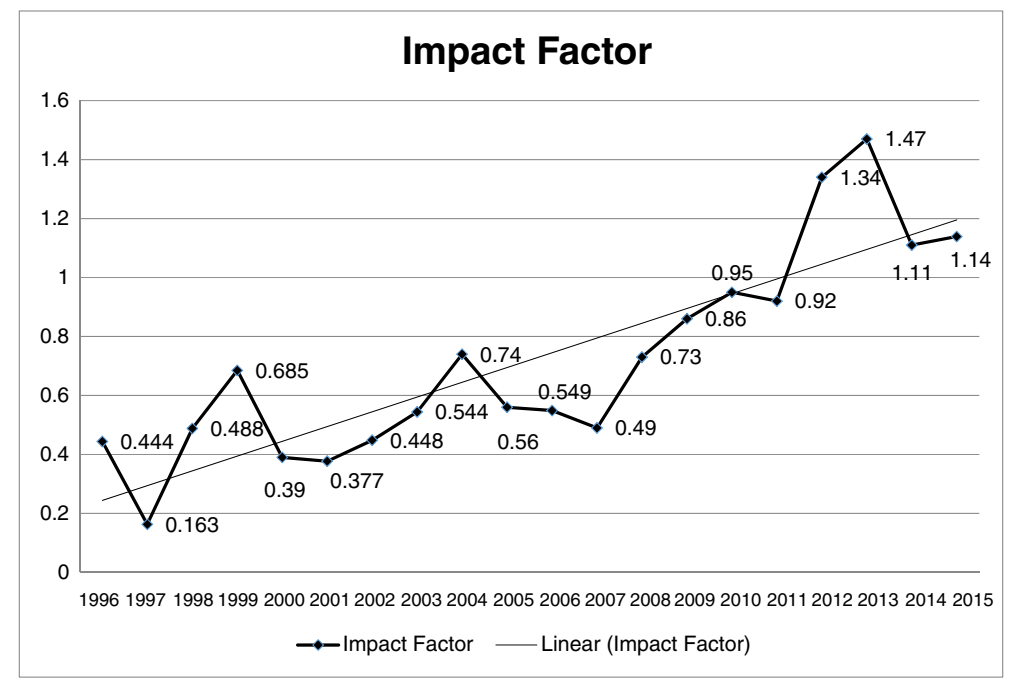

Fig. 5 Impact factor over the last 20 years and its linear trend. Source: Journal Citation Report Social Science Edition

CEPR, etc. series and institutional or discipline-specific repositories as SSRN and RePEc, increasingly, papers are also posted on personal webpages. ${ }^{10}$

With the proliferation of the working paper series and the practice of some economists to publish working papers on their own websites, working papers have changed journal practices. First, working papers push journals to move away from double-blind peer reviewing since the identity of the authors can often be easily determined based on existing working papers. ${ }^{11}$ Second, since publication lags obstruct swift dissemination of new knowledge, ${ }^{12}$ working papers are becoming substitutes for the traditional dissemination role of journals, whereby the role of journals is increasingly restricted to providing quality certification. ${ }^{13}$

Furthermore, Azar (2007) argues that by making research work timely and (mainly) openly available, the community is aware of the research before it is being published, whereby from the community's perspective quick journal publication became less important. Clearly, working papers are no substitutes for formal peer-reviewed journal publication and the resulting quality seal, but the long lag to publication is a central reason for the proliferation of working papers. ${ }^{14}$ Hence, speedy public availability and dissemination ${ }^{15}$ are the main drivers of working papers, with the implicit aim of

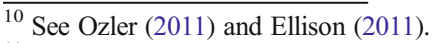

${ }^{11}$ See Blank (1993) for experimental evidence of the effects of double- vs. single-blind reviewing.

12 See Meyer (2000).

${ }^{13}$ See Ellison (2011), who presents her decline of peer-review theory, by which highly reputed authors traditionally may have used journal publications mainly to disseminate their work and nowadays will be able to doing so without publishing it in journals.

${ }^{14}$ Nowadays, online first strategies enable availability and citability in advance of the publication of an article in printed issues.

${ }^{15}$ In addition to the community, the dissemination includes also media and scholars in developing countries without formal subscription to journals.
} 
informing the community, stimulating debates, establishing priority, building reputation, and protecting research from plagiarism. ${ }^{16}$ While they generally are not peer-reviewed working papers enable a light, informal, institutional or pre-publication review, achieved through dissemination, exchange, discussions, and feedback. ${ }^{17}$

The increasing relevance of working papers may also imply a wider dissemination of wrong findings due to lacking quality assessment and in light of expected reviews until the published version. This may be aggravated by the fact that media is generally interested in new findings and thus, often, especially if findings are novel or unexpected, report, or rely on working papers. In case findings have proven wrong, readers may seldom know about the correction or read the final published version. While the quality may be partly assessed by the identity of the author, the issuer of the working paper and bibliometrics, specifically information on citations and downloads, as well as blog coverage, it is the nature of working papers to disseminate work in progress as disclaimers often signal. ${ }^{18}$ Evidence-based policy making should though not rely on working papers but rather on peer-reviewed journal publications.

As a consequence of the rapid availability and dissemination, working papers have a significant role in citations. According to Azar (2007), they account for $14 \%$ of citations having increased from $3 \%$ in 1960 and rank second in citation sources in Econometrica and American Economic Review after journals and before books followed by edited volume chapters and forthcoming articles. However, Frandsen (2009), who analyzed citation levels of working papers in economics, highlights that their measured impact is relatively low. This suggests that the number of citations to working papers underestimates the true value of working papers. Most citations to working papers are to recent papers, which appeared in the last years, since references especially prior to publication are usually updated such that the citation is to the published journal version of the paper. ${ }^{19}$ And working papers seem to increase the awareness of the article which may lead also to more journal version cites.

Nonetheless, working papers may continue to receive citations even after the respective peer-reviewed journal article has been published, e.g., because of lack of awareness of the journal publication or an easier access to the online available working paper. While these citations should be attributed to the published version of the paper and the respective journal, thus contributing to impact factor etc., the possibility of losing citations to working papers is inherent in the economics publishing sphere. As pointed out by McCabe and Snyder (2015), citations are "the currency in this market" and thus, this effect could though be costly if working papers due to their free availability attract higher citations. ${ }^{20}$ The question then is whether their open-access characteristic generates higher citations.

\footnotetext{
${ }^{16}$ See also Meyer (2000). Working papers may be included by department heads in the evaluation of scholars' research; see Harley et al. (2010).

${ }^{17}$ See Harley and Acord (2011) and Harley et al. (2010). Also, see for example the aim of NBER working papers: "They are intended to make results of NBER research available to other economists in preliminary form to encourage discussion and suggestions for revision before publication." http://www.nber.org/papers. html

${ }^{18}$ See Azar (2007) and Harley and Acord (2011).

${ }^{19}$ See Azar (2007) and Frandsen and Wouters (2009).

${ }^{20}$ See Tahamtan et al. (2016) for a comprehensive review of factors influencing citations.
} 
Since Lawrence (2001) showed that open-access articles in computer science have significantly more citations than articles which are not open access, the scientific literature in bibliometrics and information science has extensively debated the citation impacts of open access and online availability of scientific publications. ${ }^{21}$ For example, Harnad and Brody (2004) argued that articles in physics submitted to a preprint server generated four times higher citations than papers published in the same journals which were not archived on a preprint server. Hajjem et al. (2005) found that open-access articles across ten disciplines had a citation advantage of 25-250\%. While this socalled open-access effect postulates that open-access articles are cited more because they are openly available or non-open-access articles are not cited since they are not accessible, ${ }^{22}$ these and many other studies generally showed a correlation between open access and higher citations but no causality. ${ }^{23}$ In the following, the literature debated limitations, methodological flaws, and various potential biases.

Kurtz et al. (2005) uncovered two biases. First, the twofold selection or quality bias accounts for the fact that the most reputed and citable authors are more likely to make their papers openly available and especially their higher quality and thus citable contributions. Second, the early view bias or effect for papers which have posted before journal publication identifies the fact that due to their earlier availability, these papers enable earlier accumulation of citations. In the field of astronomy the authors find strong evidence for both effects but no residual open-access effect. Similarly, Moed (2007) rigorous analysis in the field of solid state physics provides evidence that after controlling for strong selection and early view biases, the open access has at best a negligible or no effect on citations. It is difficult to generalize across disciplines due to their specific publication cultures and the implied methodological aspects. ${ }^{24}$ Nonetheless, the evidence suggests that preprints or working papers in general do not have a citation impact by making research papers freely available, but it illustrates through the early view effect that they may generate citations since the papers are available earlier. This is in line with the dissemination function of working papers. ${ }^{25}$

This strand of the literature mainly focused on comparing journal articles archived in preprint archives and those not or open-access and not open-access articles in the same journals. Relatively less analysis has been applied in examining citations for working papers, i.e., publications in various earlier stages of development. ${ }^{26}$ The existing studies though seem to confirm the above findings. Frandsen (2009) found no evidence of an open-access effect on citations for working papers in economics. Specifically, the author shows that they have not experienced an increase in citations due to the free availability with the shift to online versions. Similarly, Ingwersen and Elleby (2011), who examined a working paper series of a multidisciplinary social science research institute, conclude that leaving the above biases aside working papers have no citation advantage over peer reviewed journal articles.

\footnotetext{
${ }^{21}$ See Moed (2012). See Craig et al. (2007) for a survey on the citation impact of open access.

22 See also Gargouri et al. (2010).

${ }^{23}$ See Craig et al. (2007).

${ }^{24}$ See for example Frandsen (2009) for a discussion.

${ }^{25}$ According to Moed (2007), this is also the explicit function of preprint archives.

${ }^{26}$ See Frandsen (2009).
} 
A different strand of the literature focused on the online availability effect, independently of open access, of articles on citations. ${ }^{27}$ According to McCabe and Snyder (2015), who focus their analysis on economics and business, this literature is subject to similar biases. Their analysis provides evidence of an aggregate zero online effect on citations, which though covers substantial heterogeneity. Specifically, online availability on JSTOR had a positive and significant but a not generalizable and modest effect of $10 \%$ on citations, which decreased over time. The authors argue that this decline may be due to the proliferation of working papers, whereby there is less additional citation benefit of having the published version accessible through the JSTOR platform.

Summing up, the literature does not provide any evidence for an open-access effect of working papers on citations, thereby implicitly also no evidence for systematic "stealing" of citations from published peer-reviewed journal articles. Nonetheless, sometimes, working paper references may not be updated to refer to the published journal articles. We though argue that this is an acceptable side effect of working papers. As evidence by Frandsen and Wouters (2009) shows authors generally aim for peer-reviewed journal articles in their reference list and, thus, tend to update their references, whereby the residual "stolen" citations should be modest. The evidence of a lack of open-access effect indicates as discussed by Frandsen (2009) and Craig et al. (2007) that working papers have different impacts on readership and citations. Clearly, the impact on the former reflects the advantages of working papers and their information and dissemination function. In addition, without working papers, the author and the research itself would lose citations, namely citations to the working paper prior to the journal publication, which the journal would not have received anyway. The strong evidence for the early view effect suggests that this loss would be significant, since working papers enable acceleration and early accumulation of citations. Furthermore, the combination of this latter effect and the updating of references could imply that working papers generate additional citations for peer-reviewed journal articles. Imagine a researcher being able to access early, read, and cite the working paper, while the journal article is not yet published. By the time, this researcher submits her final version for publication the peer reviewed journal article may be published and then replace the working paper in the updated references.

Clearly, working papers are working in economics: they have an important information, dissemination, and informal review function and generate early citations for the author, and while potential citation losses for the published journal article to the working paper version are expected to be small, working papers may actually generate additional citations for the journal. Peer-reviewed journal publication remains essential to provide the necessary quality certification. The proliferation of working papers has though shown that they have and will in the future reduce the marginal impact of other online or open-access channels, e.g., as limited time window open access or early view of the online version of the peer-reviewed article before print publication. ${ }^{28}$ As a tendency, working papers and published articles are complementary.

\footnotetext{
${ }^{27}$ See McCabe and Snyder (2015) for a discussion of this literature.

${ }^{28}$ See McCabe and Snyder (2015) and Ingwersen and Elleby (2011).
} 
Table 4 Articles with and without working papers and their citations

\begin{tabular}{lllllll}
\hline Indicator/year & 2010 & 2011 & 2012 & 2013 & 2014 & $2010-2014$ \\
\hline Total number of papers with WP & 33 & 28 & 34 & 35 & 21 & 151 \\
Share of published papers with WP & 0.58 & 0.47 & 0.59 & 0.57 & 0.53 & 0.55 \\
Avg. Google Scholar cites - with WP & 57.2 & 51.6 & 23.5 & 21.2 & 12.5 & 33.2 \\
Avg. Google Scholar cites - without WP & 21.6 & 25.3 & 18.0 & 12.5 & 4.4 & 16.4 \\
Avg. Web of Science cites - with WP & 10.1 & 7.2 & 3.9 & 2.8 & 1.5 & 5.1 \\
Avg. Web of Science cites - without WP & 5.6 & 5.2 & 4.1 & 2.6 & 0.5 & 3.6 \\
Avg. no of WPs-with WP & 1.7 & 1.7 & 1.2 & 1.6 & 1.4 & 1.5 \\
Total number of published papers & 57 & 59 & 58 & 61 & 40 & 275 \\
\hline
\end{tabular}

Yearly number from 2010 to 2014, and averages of this period, of articles published also as working paper, as a share of all published articles as well as the respective number of citations registered in Google Scholar and Web of Science. Data collected in December 2015. Source: Journal of Population Economics, Thompson Reuters Web of Science, Google Scholar, IDEAS/RePec

$W P$ working paper

\subsection{Journal of Population Economics: citations 2010-2014}

To provide some further insights into the topic, we have examined the citations in the Web of Science as well as Google Scholar for the papers published in the Journal of Population Economics from 2010 to $2014(N=275)$ and also whether working paper versions exist. The data (see Table 4) show that in line with McCabe and Snyder (2015) on average, more than half (55\%) of the Journal of Population Economics articles published in 2010-2014 have also been published as working papers and on average in 1.5 outlets. $^{29}$

Those articles which have also been published as working paper systematically have higher citations. Specifically, Google Scholar citations count the citations of both the article itself and the working paper version and show that articles published also as working papers get on average 2 times more citations. The Web of Science citations report counting only citations of the article itself reveals 1.4 times more citations for articles which have also been published as working papers. Clearly, as per the discussion above, this association does not imply any causation and may be a result of the early view and selection biases.

\subsection{Journal of Population Economics: most cited papers 1997-2016}

The data presented in the previous section on articles from 2010 to 2014 in the Journal of Population Economics replicates the association found in previous literature between articles also published as working papers and a higher number of received citations. We try to identify whether a potential selection bias may exist also among the most cited papers published in the Journal of Population Economics from 1997 to June 2016. Table 5 contains the top cited papers within

\footnotetext{
${ }^{29}$ One needs to take into account that this analysis does not count articles which have a different title in their working paper version.
} 
Table 5 Journal of Population Economics: most cited papers 1997-2016

\begin{tabular}{|c|c|c|c|c|c|c|}
\hline No. & Author(s) & Title & Year & WoS & Scholar & WP \\
\hline 1 & David J. McKenzie & $\begin{array}{l}\text { Measuring inequality } \\
\text { with asset indicators }\end{array}$ & $2005,18(2)$ & 119 & 406 & 1 \\
\hline 2 & $\begin{array}{l}\text { Namkee Ahn } \\
\text { and Pedro Mira }\end{array}$ & $\begin{array}{l}\text { A note on the changing } \\
\text { relationship between } \\
\text { fertility and female } \\
\text { employment rates in } \\
\text { developed countries }\end{array}$ & 2002,15 (4) & 115 & 583 & 2 \\
\hline 3 & $\begin{array}{l}\text { Barry R. Chiswick } \\
\text { and Paul W. Miller }\end{array}$ & $\begin{array}{l}\text { Immigrant earnings: } \\
\text { language skills, } \\
\text { linguistic concentrations } \\
\text { and the business cycle }\end{array}$ & 2002,15 (1) & 115 & 383 & 1 \\
\hline 4 & Daniela Del Boca & $\begin{array}{l}\text { The effect of child care } \\
\text { and part time opportunities } \\
\text { on participation and fertility } \\
\text { decisions in Italy }\end{array}$ & 2002,15 (3) & 109 & 593 & 1 \\
\hline 5 & Anna Maria Mayda & $\begin{array}{l}\text { International migration: a panel } \\
\text { data analysis of the determinants } \\
\text { of bilateral flows }\end{array}$ & $2010,23(4)$ & 106 & 458 & 2 \\
\hline 6 & Alícia Adserà & $\begin{array}{l}\text { Changing fertility rates in } \\
\text { developed countries. The } \\
\text { impact of labor market } \\
\text { institutions }\end{array}$ & 2004, 17 (1) & 100 & 403 & 0 \\
\hline 7 & Christian Dustmann & $\begin{array}{l}\text { Speaking fluency, writing fluency } \\
\text { and earnings of migrants }\end{array}$ & 1994, 7 (2) & 96 & 347 & 1 \\
\hline 8 & $\begin{array}{l}\text { Björn Gustafsson } \\
\text { and Shi Li }\end{array}$ & $\begin{array}{l}\text { Economic transformation and the } \\
\text { gender earnings gap in urban } \\
\text { China }\end{array}$ & $2000,13(2)$ & 93 & 334 & 0 \\
\hline 9 & $\begin{array}{l}\text { Amelie Constant } \\
\text { and Douglas S. Massey }\end{array}$ & $\begin{array}{l}\text { Self-selection, earnings, and } \\
\text { out-migration: a longitudinal } \\
\text { study of immigrants to Germany }\end{array}$ & $2003,16(4)$ & 86 & 338 & 1 \\
\hline 10 & Thomas Lemieux & $\begin{array}{l}\text { The changing nature of } \\
\text { wage inequality }\end{array}$ & 2008, 21 (1) & 80 & 340 & 1 \\
\hline
\end{tabular}

Citations from Web of Science from 1997 to June 2016, citations from Google Scholar retrieved on June, 30, 2016. The column WP highlights the number of times this article has been also published as a working paper. Source: Own calculations, Springer, Google Scholar, Thompson Reuters Web of Science

$W P$ working paper

this period as provided from the Web of Science, and additionally, it provides information on citations in Google Scholar and the number of times the article has also been published as a working paper. Eighty percent of these most cited articles have also been published as a working paper and if they did, then on average 1.3 times. Thus, while the latter number is slightly lower than in the previous section, the share of articles also published as a working paper is larger. Since these figures are based on the high citation volume articles, this can be interpreted as a result of a quality effect, whereby the higher quality and more citable research papers are also published as working papers. 
For these highly cited articles, we also inspected the potential early view effect by counting the Google Scholar citations until the year prior to the Journal of Population Economics publication year. Based on this crude inspection, the early view effect of working papers on citations lies between 0 and $10 \%$ with an average of $2 \%$ of existing citations.

\subsection{Journal of Population Economics: citations of lead articles 2014}

The Journal of Population Economics highlights one article as lead article of the issue and since 2014 these articles are available open access for a period of 8 weeks. The lead article and the free access to it is advertised on the publisher's and host institution's website as well as through social media channels. Taking into account the limitations of the sample being restricted to 1 year, thus, four lead articles, whereby the findings need to be interpreted with caution, Table 6 nonetheless presents some interesting insights. In 2014, each lead article had also been published as a working paper and on average 1.75 times. These figures are both larger than the above. These lead articles get on average more than three times (based on Google Scholar citations) and more than two times (based on Web of Science citations) more citations than "normal," i.e., non-lead, articles which also have been published as working papers.

Again, these facts do not enable any clear interpretation though the fact that all lead articles exist as working papers may relate to the selection or quality effect. The higher citations of lead articles relative to normal articles may in addition to being a result of the selection effect could also be a result of a signaling effect. Having chosen these papers as lead articles may signal higher quality. The fact that these articles are openly accessible for a specific time window should have no significant impact if we apply the findings from the literature and since all these papers have respective working paper versions, which would make any potential additional citation benefit even smaller.

While we are not able to verify the existence of the mentioned effects for the Journal of Population Economics without further rigorous analysis, on the basis of the existing

Table 6 Lead and normal articles published in 2014 with and without working papers and their citations

\begin{tabular}{llll}
\hline Indicator/article type & Lead articles & Normal articles & Average \\
\hline Total number of papers with WP & 4 & 17 & 21 \\
Share of published papers with WP & 1.00 & 0.47 & 0.53 \\
Average Google Scholar cites - paper with WP & 28.5 & 8.8 & 12.5 \\
Average Google Scholar cites - paper without WP & N/A & 4.4 & 4.4 \\
Average Web of Science cites - paper with WP & 2.75 & 1.2 & 1.5 \\
Average Web of Science cites - paper without WP & N/A & 0.5 & 0.5 \\
Average no of WPs for those published in WP & 1.75 & 1.3 & 1.4 \\
Total number of published papers & 4 & 36 & 40 \\
\hline
\end{tabular}

Yearly number for 2014, and average of this period, of lead and normal articles published also as working paper and the respective number of citations registered in Google Scholar and Web of Science. Data collected in December 2015. Source: Journal of Population Economics, Thompson Reuters Web of Science, Google Scholar, IDEAS/RePec

$W P$ working paper 
literature, this inspection into the citations articles leads to different interpretations. Journal of Population Economics' articles increasingly have a respective working paper version, the top cited articles to a higher degree, which may be a direct result of the quality or selection effect. The limited data on lead articles may point to a potential signaling effect.

\section{Concluding remarks}

The Journal of Population Economics has experienced very successful 30 years of publishing high-quality research in population economics. We have reviewed and highlighted some selected developments. First, the editorial developments of the Journal are comparable to those of top economics journals. Second, the Journal is indeed a global journal in reach and authorship. Third, its impact factor and rankings illustrate the success of the Journal and place and qualify it as the leading journal in population economics.

We have discussed the central role of working papers in economics and stressed that working papers are indeed working. They fulfill a crucial and valuable dissemination function in economics; the use and interpretation of their findings though has to take into account their specific nature as working papers. Peer-reviewed journal articles remain essential to provide quality control and assurance. The discussion of the literature provided insights into their citation impact, and in our interpretation, citations of journal articles rather benefit from working papers than lose citations to them. Both seem to be complements rather than substitutes, and the Journal will continue to accept discussion papers for submission.

\section{References}

Andrikopoulos A, Samitas A, Kostaris K (2016) Four decades of the Journal of Econometrics: coauthorship patterns and networks. J Econ 195(1):23-32

Azar OH (2007) The slowdown in first-response times of economics journals: can it be beneficial? Econ Inq 45(1):179-87

Blank R (1993) The effects of double-blind versus single-blind reviewing: experimental evidence. Am Econ Rev 81(5):1041-1067

Card D, DellaVigna S (2013) Nine facts about top journals in economics. J Econ Lit 51(1):144-161

Craig ID, Plume AM, McVeigh ME, Pringle J, Amin M (2007) Do open access articles have greater citation impact? A critical review of the literature. J Inf 1(3):239-248

Ellison G (2011) Is peer review in decline. Econ Inq 49(3):635-657

Frandsen TF (2009) The effects of open access on un-published documents: a case study of economics working papers. J Inf 3(2):124-133

Frandsen TF, Wouters P (2009) Turning working papers into articles: an exercise in micro-bibliometrics. J Am Soc Inf Sci Technol 60(2):728-739

Gargouri Y, Hajjem C, Larivière V, Gingras Y, Carr L, Brody T, Harnad S (2010) Self-selected or mandated, open access increases citation impact for higher quality research. PLoS One 5(10):e13636

Hajjem C, Harnad S, Gingras Y (2005) Ten-year cross-disciplinary comparison of the growth of open access and how it increases research citation impact. Bull Tech Comm Data Eng 28(4):39-47

Harley D, Acord SK (2011), Peer review in academic promotion and publishing: its meaning, locus, and future. Research and Occasional Papers Series, Centre for Studies in Higher Education 
Harley D, Acord SK, Earl-Novell S, Lawrence S, King CJ (2010) Assessing the future landscape of scholarly communication: an exploration of faculty values and needs in seven disciplines. Center for Studies in Higher Education, Berkeley

Harnad S, Brody T (2004), Comparing the impact of open access (OA) vs. non-OA articles in the same journals, D-Lib Ma 10:6

Ingwersen P, Elleby A (2011) Do open access working papers attract more citations compared to printed journal articles from the same research unit?, Proceedings of the ISSI 2011 Conference: 13th International Conference of the International Society for Scientometrics \& Informetrics, Durban, South Africa, 04-07 July 2011, by Noyons Ed, Ngulube P, Leta J (eds.), ISSI \& University of Zululand: South Africa. pp. 327-332

Kurtz MJ, Eichhorn G, Accomazzi A, Grant C, Demleitner M, Henneken E, Murray SS (2005) The effect of use and access on citations. Inf Process Manag 41(6):1395-1402

Lawrence S (2001) Online or invisible? Nature 411(6837):521

McCabe MJ, Snyder CM (2015) Does online availability increase citations? Theory and evidence from a panel of economics and business journals. Rev Econ Stat 97(1):144-165

Meyer D (2000) On the information and selection function of economics articles — claims and reality. J Post Keynesian Econ 23(1):49-75

Moed HF (2007) The effect of “Open Access" upon citation impact: an analysis of ArXiv's condensed matter section. J Am Soc Inf Sci Technol 58(13):2047-2054

Moed HF (2012) Does open access publishing increase citation or download rates? Res Trends 28, May 2012

Ozler B (2011) Working papers are not working, Development Impact Blog, The World Bank, 30.06.2011, http://blogs.worldbank.org/impactevaluations/working-papers-are-not-working

Tahamtan I, Afshar AS, Ahamdzadeh K (2016) Factors affecting number of citations: a comprehensive review of the literature. Scientometrics 107(3):1195-1225

Zimmermann KF (1997) Editorial: the second decade. J Popul Econ 10(1):1-2 